This Section of Epidemiology and Psychiatric Sciences appears in each issue of the Journal to stress the relevance of epidemiology for behavioral neurosciences, reporting the results of studies that explore the use of an epidemiological approach to provide a better understanding of the neural basis of major psychiatric disorders and, in turn, the utilization of the behavioural neurosciences for promoting innovative epidemiological research.

The ultimate aim is to help the translation of most relevant research findings into every-day clinical practice. These contributions are written in house by the journal's editorial team or commissioned by the Section Editor (no more than 1000 words, short unstructured abstract, 4 key-words, one Table or Figure and up to ten references).

Paolo Brambilla, Section Editor

\title{
Brain anatomy of autism spectrum disorders II. Focus on amygdala
}

\author{
M. Bellani ${ }^{1 *}$, S. Calderoni ${ }^{2}$, F. Muratori ${ }^{2,3}$ and P. Brambilla ${ }^{4,5}$ \\ ${ }^{1}$ Department of Public Health and Community Medicine, Section of Psychiatry and Section of Clinical Psychology, Inter-University Center for \\ Behavioural Neurosciences (ICBN), University of Verona, Verona, Italy \\ ${ }^{2}$ IRCCS Stella Maris Foundation, Pisa, Italy \\ ${ }^{3}$ Department of Child Neurology and Psychiatry, University of Pisa, Italy \\ ${ }^{4}$ Department of Experimental Clinical Medicine, Inter-University Center for Behavioural Neurosciences (ICBN), University of Udine, Udine, Italy \\ ${ }^{5}$ Department of Psychiatry and Behavioral Sciences, University of Texas Medical School at Houston, TX, USA
}

This brief review encompasses the key findings of structural Magnetic Resonance Imaging (sMRI) research on amygdala volume in autism spectrum disorders (ASD). We also highlight the possible correlation between the autistic behavioural phenotype and amygdala alteration.

Received 17 May 2013; Revised 29 May 2013; Accepted 29 May 2013; First published online 2 July 2013

Key words: Amygdala, Autism Spectrum Disorders (ASD), Structural Magnetic Resonance Imaging (sMRI), Volumes.

The lack of reliable, specific brain biomarkers for autism spectrum disorders (ASD) results in a diagnosis based on behavioural criteria (Muratori et al. 2011). However, recent structural magnetic resonance imaging (sMRI) studies provide new insights into the neuroanatomical substrate of ASD, suggesting the involvement of the corpus callosum and the fronto-parieto-temporal regions (Mengotti et al. 2011; Bellani et al. 2013). Among these latter, the amygdala is a relatively small subcortical brain region located in the anteromedial temporal lobe and included in the limbic system. It contains at least 13 distinct nuclei,

* Address for correspondence: Dr M. Bellani, Department of Public Health and Community Medicine, Section of Psychiatry and Section of Clinical Psychology, University of Verona, Piazzale L.A. Scuro 10, 37134 Verona, Italy.

(Email: marcella.bellani@univr.it; paolo.brambilla@uniud.it) among which four major nuclei (the lateral, basal, accessory basal and central nuclei) with unique patterns of connectivity with other brain regions. In particular, the central nucleus, a phylogenically primitive part, communicates mostly with brainstem and olfactory centres, while the basolateral nuclei are strongly connected to the neocortex. Besides its primary role of monitoring the environment for potential danger and modulating levels of vigilance, the amygdala plays a seminal contribution to social behaviour. Specifically, it is implicated in several cognitive functions, including social cognition, recognition of emotions, attribution of emotional valence to stimuli and regulation of the personal space. These findings have led researchers to postulate the 'amygdala theory of autism' since the amygdala may be primarily involved in the socio-emotional impairment peculiar of ASD subjects (Baron-Cohen et al. 2000). 
Table 1. Summary of studies published between 2006-2012 investigating amygdala volumetry in patients with ASD compared with control subjects*

\begin{tabular}{|c|c|c|c|c|c|}
\hline Study & Subjects & Age in years (S.D.) & Full-scale IQ & Field strength $(\mathrm{T})$ & Significant findings in ASD relative to controls \\
\hline \multirow[t]{2}{*}{ Dziobek et al. (2006) } & 17 AS & 41.4 (9.9) & $113(6)$ & n.r. & No differences in bilateral amygdala volume \\
\hline & $17 \mathrm{TD}$ & $40.2(13.0)$ & $115(5)$ & & \\
\hline \multirow[t]{2}{*}{ Nacewicz et al. (2006) } & $12 \mathrm{ASD}$ & $16.8(4.5)$ & n.r. & 3.0 & No differences in bilateral amygdala volume \\
\hline & $12 \mathrm{TD}$ & $17.0(2.9)$ & n.r. & & \\
\hline \multirow[t]{2}{*}{ Nacewicz et al. (2006) } & 16 ASD & $14.3(4.7)$ & $97(26)$ & 3.0 & $\begin{array}{l}\text { Reduction in bilateral amygdala volume, particularly in the older } \\
\text { subgroup (>12.5 years) }\end{array}$ \\
\hline & $14 \mathrm{TD}$ & $13.7(3.9)$ & $122(13)$ & & \\
\hline \multirow[t]{2}{*}{ Palmen et al. (2006) } & 42 HFA & $15.6(5.3)$ & $110.7(16.9)$ & 1.5 & No differences in bilateral amygdala volume \\
\hline & $42 \mathrm{TD}$ & $15.3(5.4)$ & $107.6(13.4)$ & & \\
\hline \multirow[t]{2}{*}{ Corbett et al. (2009) } & 12 HFA & $9.0(1.6)$ & $90.7(13.8)$ & 1.5 & No differences in bilateral amygdala volume \\
\hline & $15 \mathrm{TD}$ & $9.2(1.4)$ & $115.7(15.8)$ & & \\
\hline \multirow[t]{3}{*}{ Mosconi et al. (2009) } & $50 \mathrm{ASD}$ & $2.7(0.3)$ & $53.8(9.0)$ & 1.5 & Enlargement in bilateral amygdala volume \\
\hline & $11 \mathrm{DD}$ & $2.8(0.4)$ & $56.6(16.9)$ & & \\
\hline & $22 \mathrm{TD}$ & $2.5(0.5)$ & $105.8(16.0)$ & & \\
\hline \multirow[t]{3}{*}{ Mosconi et al. $(2009)^{\ddagger}$} & $31 \mathrm{ASD}$ & $5.0(0.4)$ & $56.6(16.9)$ & 1.5 & Enlargement in bilateral amygdala volume \\
\hline & $6 \mathrm{DD}$ & $5.0(0.5)$ & $56.0(6.8)$ & & \\
\hline & $14 \mathrm{TD}$ & $4.6(0.5)$ & $112.3(12.3)$ & & \\
\hline \multirow[t]{6}{*}{ Schumann et al. (2009) } & $32(\mathrm{~m}) \mathrm{AD}$ & 36 (7.2) months & $58(20)$ & 1.5 & $\begin{array}{l}\text { Enlargement in bilateral amygdala volume in AD, particularly } \\
\text { evident in ( } \mathrm{f} \text { ) }\end{array}$ \\
\hline & $9(\mathrm{f}) \mathrm{AD}$ & 36 (4.7) months & $57(23)$ & & \\
\hline & 6 (m)PDD-NOS & 36 (9.1) months & $93(32)$ & & \\
\hline & 3 (f)PDD-NOS & 56 (6.1) months & $63(19)$ & & \\
\hline & $28(\mathrm{~m}) \mathrm{TD}$ & 34 (7.1) months & $111(17)$ & & \\
\hline & 11 (f)PDD-NOS & 37 (6.4) months & $115(15)$ & & \\
\hline \multirow[t]{2}{*}{ Groen et al. (2010) } & $23 \mathrm{AD}$ & $15.1(1.9)$ & $99.5(20.1)$ & 1.5 & Enlargement in right amygdala volume \\
\hline & $29 \mathrm{TD}$ & $15.6(1.7)$ & $104.9(9.6)$ & & \\
\hline \multirow[t]{2}{*}{ Kim et al. (2010) } & 31 ASD & $6.5(0.3)$ & $70.9(23.2)$ & 1.5 & Enlargement in bilateral amygdala volume (laterobasal subregions) \\
\hline & $20 \mathrm{TD}$ & $6.5(0.4)$ & $115.6(13.9)$ & & \\
\hline \multirow[t]{2}{*}{ Murphy et al. (2012) } & 32 AS & $23(11)$ & $108(13)$ & 1.5 & Enlargement in bilateral amygdala volume \\
\hline & $32 \mathrm{TD}$ & $23(11)$ & $111(15)$ & & \\
\hline \multirow[t]{2}{*}{ Nordahl et al. (2012) } & 85 ASD & 36.8 (5.7) months & $63.4(22.1)$ & 3.0 & Enlargement in bilateral amygdala volume \\
\hline & $47 \mathrm{TD}$ & 36.9 (5.3) months & $103.8(11.8)$ & & \\
\hline
\end{tabular}




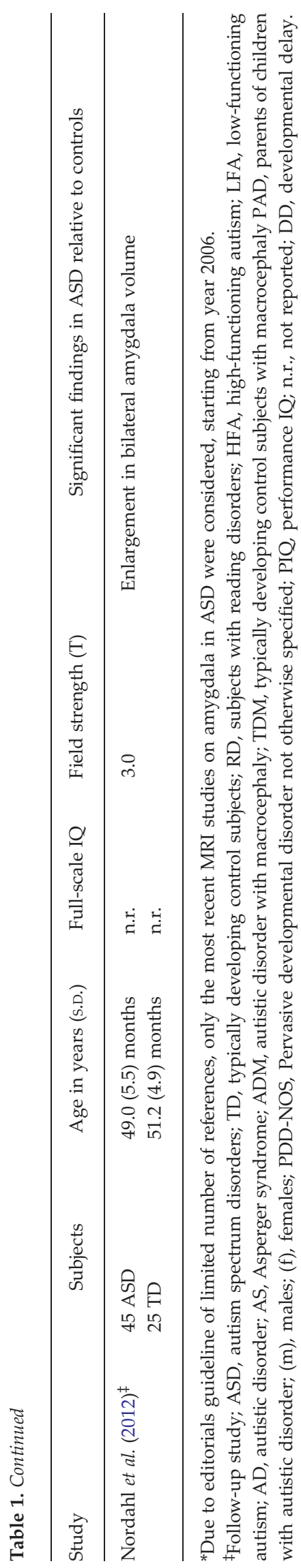

However, the presence of amygdala structural abnormalities in ASD is unclear since previous research has produced conflicting results. Indeed, increased, decreased and preserved volumes have been shown in studies using manual tracing to define the amygdala morphology $(8,1$ and 4 studies, respectively; see Table 1). Nonetheless, there is some evidence for age-related effects on amygdala volumes, confirmed by a recent meta-analysis of sMRI studies in ASD (Stanfield et al. 2008). Specifically, ASD toddlers and children frequently show significantly increased bilateral amygdala volumes relative to age-matched controls (Mosconi et al. 2009; Schumann et al. 2009; Kim et al. 2010; Nordahl et al. 2012), whereas older adolescents and adults either reduced (Nacewicz et al. 2006), or preserved size (Corbett et al. 2009; Dziobek et al. 2006; Nacewicz et al. 2006; Palmen et al. 2006). Despite the age of the subject population seems to be a critical factor, some heterogeneity in the rate of amygdala growth within the ASD population of the same age-range has been detected. Accordingly, a recent longitudinal study pointed to three ASD subgroups in the amygdala developmental time course between two and four years of age, i.e. (1) rapid growth, (2) slow growth, and (3) growth trajectories consistent with those of typically developing children (Nordahl et al. 2012). The behavioural correlates of different amygdala growth patterns, unfortunately, are not reported in this study. In contrast, very few papers performed a separate analysis by sex, showing more pronounced amygdala enlargement in female children with ASD (Schumann et al. 2009) compared with age- and gender-matched typically developing controls. These preliminary findings suggest a potential different pattern of amygdala development in ASD in accordance to gender.

Interestingly, a correlation between the severity of core ASD symptoms and amygdala anatomy has been detected in several studies, with a different trajectory in accordance to age. Indeed, a direct correlation between amygdala volumes and degree of social and communicative impairment has been found in toddlers (Munson et al. 2006; Schumann et al. 2009), and younger children with ASD (Kim et al. 2010). In contrast, smaller amygdalae associated with deficits of social reciprocity in older ASD children (Nacewitz et al. 2006) and with restricted-repetitive behaviour in adult subjects with Asperger syndrome (Dziobek et al. 2006).

In conclusion, there is evidence that amygdala volumes are enlarged in toddlers and younger children with ASD and correlate with social ability impairment. Nonetheless, some key issues remain to be clarified, specifically: (1) whether the onset of amygdala overgrowth in ASD is already present at birth or during 
the postnatal brain growth; (2) at which age the amygdala developmental trajectory decelerates in ASD, leading to attenuated differences with typically developing controls; (3) if gender and ASD phenotype (i.e., socio-communicative deficits) play a role on the above mentioned amygdala maturation. Only future prospective studies that follow over time, through multiple MRI scans, high-risk neonates well-characterized from the clinical point of view could provide insightful information into each of these research questions.

\section{Acknowledgements}

None.

\section{Financial Support}

S. C. was partly supported by the Italian Ministry of Health and by Tuscany Region with the grant 'GR-2010-2317873'. F. M. and S. C. were partly supported by the European Union (The MICHELANGELO Project). The other authors received no specific grant from any funding agency, commercial or not-for-profit sectors for this publication.

\section{Conflict of Interest}

None.

\section{Ethical Standards}

The authors declare that no human or animal experimentation was conducted for this work.

\section{References}

Baron-Cohen S, Ring HA, Bullmore ET, Wheelwright S, Ashwin C, Williams SC (2000). The amygdala theory of autism. Neuroscience and Biobehavioral Reviews 24, 355-364.

Bellani M, Calderoni S, Muratori F, Brambilla P (2013). Brain anatomy of autism spectrum disorders I. Focus on corpus callosum. Epidemiology and Psychiatric Sciences, March 26. [Epub ahead of Print]. doi: 10.1017/ s2045796013000139.

Corbett BA, Carmean V, Ravizza S, Wendelken C, Henry ML, Carter C, Rivera SM (2009). A functional and structural study of emotion and face processing in children with autism. Psychiatry Research: Neuroimaging 173, 196-205.

Dziobek I, Fleck S, Rogers K, Wolf OT, Convit A (2006). The 'amygdala theory of autism' revisited: linking structure to behavior. Neuropsychologia 44, 1891-1899.
Groen W, Teluij M, Buitelaar J, Tendolkar I (2010). Amygdala and hippocampus enlargement during adolescence in autism. Journal of the American Academy of Child and Adolescent Psychiatry 49, 552-560.

Kim JE, Lyoo IK, Estes AM, Renshaw PF, Shaw DW, Friedman SD, Kim DJ, Yoon SJ, Hwang J, Dager SR (2010). Laterobasal amygdalar enlargement in 6- to 7-year-old children with autism spectrum disorder. Archives of General Psychiatry 67, 1187-1197.

Mengotti P, D'Agostini S, Terlevic R, De Colle C, Biasizzo E, Londero D, Ferro A, Rambaldelli G, Balestrieri M, Zanini S, Fabbro F, Molteni M, Brambilla P (2011). Altered white matter integrity and development in children with autism: a combined voxel-based morphometry and diffusion imaging study. Brain Research Bullettin 84, 189-195.

Mosconi MW, Cody-Hazlett H, Poe MD, Gerig G, Gimpel-Smith R, Piven J (2009). Longitudinal study of amygdala volume and joint attention in 2- to 4-year-old children with autism. Archives of General Psychiatry 66, 509-516.

Munson J, Dawson G, Abbott R, Faja S, Webb SJ, Friedman SD, Shaw D, Artru A, Dager SR (2006). Amygdalar volume and behavioral development in autism. Archives of General Psychiatry 63, 686-693.

Muratori F, Narzisi A, Tancredi R, Cosenza A, Calugi S, Saviozzi I, Santocchi E, Calderoni S (2011). The CBCL 1.5-5 and the identification of preschoolers with autism in Italy. Epidemiology and Psychiatric Sciences 20, 329-338.

Murphy CM, Deeley Q, Daly EM, Ecker C, O'Brien FM, Hallahan B, Loth E, Toal F, Reed S, Hales S, Robertson DM, Craig MC, Mullins D, Barker GJ, Lavender T, Johnston P, Murphy KC, Murphy DG (2012). Anatomy and aging of the amygdala and hippocampus in autism spectrum disorder: an in vivo magnetic resonance imaging study of Asperger syndrome. Autism Research 5, 3-12.

Nacewicz BM, Dalton KM, Johnstone T, Long MT, McAuliff EM, Oakes TR, Alexander AL, Davidson RJ (2006). Amygdala volume and nonverbal social impairment in adolescent and adult males with autism. Archives of General Psychiatry 63, 1417-1428.

Nordahl CW, Scholz R, Yang X, Buonocore MH, Simon T, Rogers S, Amaral DG (2012). Increased rate of amygdala growth in children aged 2 to 4 years with autism spectrum disorders: a longitudinal study. Archives of General Psychiatry 69, 53-61.

Palmen SJ, Durston S, Nederveen H, Van Engeland H (2006). No evidence for preferential involvement of medial temporal lobe structures in high-functioning autism. Psychological Medicine 36, 827-834.

Schumann CM, Barnes CC, Lord C, Courchesne E (2009). Amygdala enlargement in toddlers with autism related to severity of social and communication impairments. Biological Psychiatry 66, 942-949.

Stanfield AC, McIntosh AM, Spencer MD, Philip R, Gaur S, Lawrie SM (2008). Towards a neuroanatomy of autism: a systematic review and meta-analysis of structural magnetic resonance imaging studies. European Psychiatry 23, 289-299. 